\title{
Gabriel Moreno González, Estabilidad presupuestaria y constitución: fundamentos teóricos y aplicación desde la Unión Europea
}

(2019) Tirant lo Blanch Valencia, $465 \mathrm{pp}$.

\author{
Pedro García Guijarro \\ Universitat de Valencia \\ ORCID ID 0000-0003-3526-3030 \\ pedrogarciaguijarro1@gmail.com
}
Cita recomendada:
García Guijarro, P. (2020). Gabriel Moreno González, Estabilidad presupuestaria y constitución: fundamentos teóricos y aplicación desde la Unión Europea. Eunomía, Revista en Cultura de la Legalidad, 18, pp. 424-429.
doi: https://doi.org/10.20318/eunomia.2020.5291

En su cada vez más postergado De Cive, sentenciaba Hobbes al individuo con un escueto "Homo homini lupus» a una eterna competencia intrínseca al ser humano en pos de la obtención de situaciones fácticas de poder que le garantizasen preeminencia y seguridad sobre el resto de hombres en un inestable e indeseable estado de naturaleza primigenio. Como uno de los pilares fundamentales de las futuras corrientes contractualitas iniciadas en Europa, esta concepción de la naturaleza humana dejará una clara impronta en la filosofía política venidera por el inevitable corolario que lleva aparejada: la fundación de una sociedad edificada sobre un pacto original y regida por una soberanía a la que todo ciudadano queda sometido.

Tras la II Guerra Mundial, la Europa de los estados-nación que Hobbes parecía ya vislumbrar es una realidad, y en el seno de sus sistemas políticos se alza una nueva concepción del Estado que pretende superar el liberalismo decimonónico y aplacar cualquier resurgimiento y extensión de los totalitarismos que habían sumido el viejo continente en la barbarie, el Estado social y democrático de derecho. Esta nueva realidad, surgida del pacto tácito entre el capital y el trabajo en unas sociedades donde el primero había perdido su tradicional hegemonía, será 
cuestionada desde el marco teórico por dos escuelas neoliberales que marcarán intensamente el devenir del proyecto de integración europeo, el Ordoliberalismo y la Economía constitucional.

El presente libro que recensionamos centra su atención en el desarrollo teórico de estas dos escuelas y sus primeras aplicaciones prácticas; en cómo sus propuestas económicas y políticas afectarán al proceso de integración europea; y cómo esta afectación logrará, progresivamente, mutar los principios económicos y políticos comunitarios hasta convertirlos en una nueva realidad jurídico-económica que Gabriel Moreno bautiza como «constitución económica neoliberal». Es por ello que una lectura pausada y reflexiva de la obra nos permitirá comprender en esencia los nuevos principios sobre los que se asienta la actual Unión Europea y, sobre todo, nos dará las llaves para entender holísticamente los confusos procedimientos económicos europeos juridificados tras la crisis económica del 2008.

La obra está dividida en cuatro partes. En la primera se pretende desgranar y estructurar el contenido teórico de las escuelas Ordoliberal y de Economía constitucional en un exitoso intento de establecer la genealogía de las ideas que fundamentarán la posterior mutación de los principios económicos y políticos de la UE, así como las primeras manifestaciones de la Golden rule (estabilidad presupuestaria) en los Estados Unidos. En la segunda parte se trata de dar luz al rocambolesco ejercicio de juridificación en la Unión Europea de la ya mentada estabilidad presupuestaria, repasando la tríada de mecanismos que han hecho posible este nuevo conglomerado jurídico, siempre con la presencia de la competencia ordoliberal como realidad paralela al mismo. Finalmente, el autor teoriza y desarrolla el concepto de Constitución Neoliberal de la UE como inferencia última de los procesos comprehendidos en la segunda parte, con el objetivo de asentarlo para una mejor comprensión y estudio de las actuales dinámicas europeas.

Gabriel Moreno inicia su profundización en la genealogía de las ideas de las teorías neoliberales con el Coloquio de Lippman (1938), reunión de los más prominentes pensadores liberales en que se plantea la necesidad de frenar las tendencias colectivistas y fascistas que parecían estar superando el liberalismo clásico, presentando como alternativa una refundación en la forma del liberalismo, convertido en un neoliberalismo que repudiase el laissez-faire manchesteriano, la absoluta separación del Estado de la política y que emplazara al Estado a regular los procesos económicos de tal forma que la libertad de mercado y la competencia volvieran a erigirse en los cimientos del progreso social. Pese al estallido de la II Guerra mundial y la dispersión de los participantes del coloquio, con la posguerra se reorganizaron dos escuelas herederas de los principios adoptados en el mismo: la Austroamericana -Hayek, Von Mises...-, en la que todavía se mantenían ciertas reminiscencias de laissez-faire reconducido, y la Escuela de Friburgo, punto de inicio de las tesis ordoliberales que nos atañen.

El ordoliberalismo alemán, huyendo del esquema liberal de una realidad sociopolítica separada del marco económico, plantea la actuación regulatoria del Estado en pos del libre mercado y la competencia como una decisión puramente política, alejada absolutamente de planteamientos iusnaturalistas que conciban el mercado como autorregulable. Con ello y mediante argumentos historicistas, proponen la idea de que, en términos marxistas, la superestructura -el Estado y el marco institucional- influye de igual o superior forma a como lo hace la propia estructura -realidad socioeconómica- sobre la primera, sin plantearse que a lo largo de la historia de los tiempos, a la que aludía Eucken, cuando el propio Estado ha influido en la realidad social, éste ya estaba cooptado por los intereses y agentes 
económicos que pretendían hacer progresar la realidad material hacia la tendencia económica predominante, con lo que el marco institucional seguiría subordinado a la estructura social.

No obstante y como bien se resalta en esta primera sección, el concepto de la competencia que desarrolla la Escuela de Friburgo se convertirá en clave de bóveda de sus enunciados económicos y de los primeros estadios de la Comunidad Europea, considerando que una sociedad donde la regulación de los intercambios materiales y la libertad de mercado están garantizados y perfectamente regulados desde el Estado permitirá el progresivo avance social, sistema al que denominaron como economía social de mercado y que ha ido incorporándose al acerbo jurídico europeo hasta su última expresión en el artículo 3.3 del Tratado de la Unión Europea.

Por su parte, a principios de los años 70 y de la mano de James Buchanan, asistimos al surgimiento de una nueva escuela neoliberal esta vez en los Estados Unidos, la Economía constitucional. No en vano citábamos al inicio de la recensión a Hobbes, sino para evocar cómo Buchanan partirá de la misma concepción del hombre en un estado de naturaleza salvaje y competitivo, para así cimentar sus postulados económicos. No obstante, su contractualismo se distingue novedosamente de la "selva hobbesiana" al proclamar que existe sociedad y tendencias cooperativas antes del contrato original, pese a la evidente debilidad de las mismas en un contexto de inseguridad y desregulación. Gracias a este matiz, el economista norteamericano se permite concebir una situación post-contrato en la que los privilegios económicos de la sociedad primitiva del estado de naturaleza se mantienen, potenciando e institucionalizando la competencia económica sin necesidad de recurrir a la violencia, en clara concordancia con los postulados ordoliberales que amparaban la misma vocación por el principio de competencia. Empero, la Economía constitucional tendrá presente los peligros del «leviatán» desatado que podría nacer de este momento constituyente y acabar, por ende, derivando hacia un intervencionismo económico que anulara el principio de competencia y los privilegios originales necesarios para Buchanan en toda sociedad de libre mercado. Es por esto que tratará de frenar tal posibilidad a través de varias propuestas político-económicas de entre las que destaca, a raíz de su prodigalidad práctica, la estabilidad presupuestaria. La misma debería ser utilizada para bloquear la capacidad del Estado de incurrir en un déficit excesivo logrando así, junto a otros contrapesos, una reducción de la expansión burocrática e intervencionista del Estado que le permita interferir en los procesos del libre mercado y la competencia.

Finalmente, se cierra la primera parte analizando la continuidad de la Golden Rule (estabilidad presupuestaria) en los Estados Unidos, su proceso de juridificación estatal y los posteriores intentos de elevarla hasta la Constitución federal estadounidense. Plantea especial interés el estudio que se realiza en este capítulo sobre la institucionalización del principio puesto que, al contrario de lo que ha ocurrido en la UE, ésta se inició desde los Estados tendiendo hacia la convergencia federal (bottom up). Partiendo de unos Estados convencidos sobre la necesidad de proteger la estabilidad presupuestaria a nivel constitucional, ya que la administración federal gestiona el mayor presupuesto del país, se propone a partir de 1975 la convocatoria de una convención constituyente en virtud del artículo $\mathrm{V}$ de la Constitución estadounidense, procedimiento que capta nuestra atención ya que, como bien se explica en el libro, nunca antes se había utilizado, prefiriendo la aprobación por mayoría cualificada en las dos cámaras legislativas del Congreso Federal. Este nuevo movimiento que pretendía frenar, en términos buchanianos, las dinámicas despilfarradoras de la administración federal requería el apoyo de 34 Estados para promover una convención, pero hubo de enfrentarse a la reacción de 
la presidencia estadounidense y a las resistencias dentro de ambos partidos, por lo que finalmente no recabó el apoyo necesario y fue bloqueada en 1979. Sin embargo, hemos de tener presente como una realidad actual la posibilidad que se alumbra al final de este apartado, ya que las peticiones estatales que se aprobaron para convocar la convención se mantienen en vigor y no decaen en sus efectos a no ser que se dé una votación igual en las asambleas legislativas de los Estados que las promulgaron, debido a lo cual actualmente se mantienen 28 de tales peticiones y no deja de ser lejana la posibilidad de la reanudación del proceso de la convención constitucional, menos aún si tenemos presente lo reciente del último intento de enmienda constitucional, por vía de las asambleas legislativas, de mayo de 2016, precisamente con el mismo objetivo de institucionalizar la estabilidad presupuestaria.

En lo referente a la patente incardinación del principio de estabilidad presupuestaria en las diferentes etapas de la integración europea, Gabriel Moreno realiza un pormenorizado análisis de los tres principales mecanismos que afianzan la primera dentro del complejo entramado institucional europeo e incluso fuera de su misma estructura jurídico política. El Pacto de Estabilidad y Crecimiento (PEC) inaugura la triada de mecanismos en 1997 como consecuencia de las directrices marcadas en el Tratado de Maastrich (1992), en pos de un mayor ahondamiento en la tercera fase de la Unión Económica y Monetaria europea mediante el reforzamiento de la estabilidad presupuestaria. Teniendo en cuenta el método de elaboración de los otros dos sistemas, el PEC resalta entre los mismos de forma positiva al haber sido aprobado siguiendo los procedimientos comunitarios con el Reglamento 1466/1997 y el Reglamento 1467/1997 del Consejo Europeo. Este primer paso se afianzará en el 2011 y 2013 con el six pack y el two pack respectivamente, conjunto de Reglamentos y directivas europeas para reforzar los vertientes preventivas y correctivas del PEC, estableciendo un máximo del $60 \%$ de deuda pública en relación con el PIB nacional y un máximo de $0.5 \%$ de déficit anual, a la vez que se formalizan sistemas preventivos de control financiero y presupuestario. Importante destacar también cómo la modificación al Reglamento 1466/1997, aprobada en 2011, refuerza en grado sumo la vertiente correctiva del pacto al incorporar un novedoso sistema de mayoría cualificada inversa en el Consejo Europeo, siendo necesario un acuerdo para que las sanciones automáticas a los Estados infractores decaigan, al contrario de lo que ocurría antes de la reforma cuando para aplicar la sanción era necesario una mayoría cualificada del consejo.

Por otro lado, el 2 de febrero de 2012, los Estados participantes en la Eurozona firman el Tratado del Mecanismo de Europeo de Estabilidad (MEDE) como sustituto definitivo de la Facilidad Europea de Estabilidad Financiera, sociedad limitada de carácter instrumental utilizada por los Estados participantes en la misma para aprobar paquetes de ayuda financiera con los que apoyar aquellos países más afectados por la crisis económica del 2008, a cambio de que estos realizaran sendos reajustes presupuestarios en el contexto de la política de austeridad europea. Lo sorprendente de ambas estructuras es el hecho de que fueran diseñadas y aprobadas fuera del marco comunitario recurriendo a un tratado intergubernamental de derecho internacional entre Estados partes, en lo que se reconoce en la obra como una de las primeras «huidas» del Derecho Europeo con el fin de sustraer al MEDE y a sus mecanismos de la supervisión de las instituciones democráticas europeas, especialmente del Parlamento Europeo.

Pese al interés jurídico político que suscita el opaco proceso de aprobación del MEDE, resulta profundamente sugerente analizar, tal y como se hace en este segundo capítulo del libro, las resistencias de los tribunales constitucionales nacionales a las disposiciones del tratado. Se observa cómo éstos adaptan el 
contenido de sus resoluciones a aquello dictado por el Tribunal Constitucional Alemán (TCA) en su sentencia de 7 de diciembre de 2011, ahondando en su jurisprudencia establecida al reafirmar como inconstitucional una transferencia excesiva de competencias presupuestarias a una organización supranacional, ligando el concepto de democracia y soberanía nacional residida en el parlamento con la competencia presupuestaria del mismo. Por tanto, el TCA reconoce la constitucionalidad del MEDE siempre y cuando Alemania retenga suficiente control sobre el nuevo mecanismo como para prevenir desequilibrios excesivos en sus presupuestos, lo cual se logra a partir del procedimiento de unanimidad que se sigue a la hora de aprobar los paquetes financieros. Sin embargo, el mecanismo de «urgencia» del tratado permite aprobar tales paquetes con un $85 \%$ de votos de los Estados parte a favor, votos ponderados en razón de las aportaciones financieras estatales al fondo común. Aquí es donde resulta más confusa la resistencia de algunos tribunales como la del Tribunal Constitucional Estonio (TCE). Éste, pese a reconocer que el MEDE podría ser inconstitucional al no alcanzar el país báltico la aportación del $15 \%$ necesaria para vetar los procedimientos de urgencia, mantiene la constitucionalidad del tratado arguyendo rocambolescas relaciones entre la aprobación del mismo y su legitimidad en base al sustrato democrático de las instituciones europeas como promotoras del MEDE, dejando pasar por alto que el tratado ha sido aprobado por mecanismos extracomunitarios de derecho internacional y sin participación alguna de instituciones europeas. Partiendo de tales inconsistencias, en cierto modo repetidas por el resto de tribunales constitucionales europeos, podríamos afirmar que la sentencia del TCE contradice el principio procesal básico de congruencia entre los fundamentos jurídicos expuestos, la inconstitucionalidad del MEDE por afectar al núcleo de la soberanía presupuestaria estonia; y el fallo, la decisión del tribunal de aceptar su constitucionalidad.

Terminando con esta segunda parte, el autor examina el Tratado de Estabilidad Coordinación y Gobernanza (TECG) del 2 de marzo de 2012, con el que se cierra la triada de mecanismos de la estabilidad presupuestaria. En resumidas cuentas, el nuevo tratado focaliza su atención en dos objetivos: reforzar la exigibilidad de un máximo de $0.5 \%$ de déficit público y un $60 \%$ de deuda pública en relación con el PIB y, lo más relevante para este análisis, la obligación de transponer a los ordenamientos jurídicos nacionales la estabilidad presupuestaria en un nivel supra legal siguiendo un procedimiento de "constitucionalización flexible», es decir, protegiendo la norma transpuesta por encima del nivel legal de forma vinculante y permanente, pretendiendo su constitucionalización pero sin exigirla explícitamente. Partiendo de una ya de por sí amplia indefinición del objetivo de constitucionalización flexible, se suma el hecho de que, de nuevo, este tratado fue aprobado huyendo de los procedimientos comunitarios y recurriendo a un acuerdo intergubernamental de derecho internacional, pretendiendo además exigir a los Estados partes una reforma de sus Constituciones.

Por si no fuera poco, el propio tratado dota al Tribunal de Justicia de la Unión Europea de la facultad para conocer del incumplimiento de los procesos de trasposición constitucional flexible de la estabilidad presupuestaria, transposición de obligado cumplimiento para los Estados partes, otorgando así competencias desde un tratado extracomunitario a un órgano clave en las instituciones europeas como es el TJUE, en lo que de nuevo es un claro intento de huir de los mecanismos democráticos europeos y elevar a lo indisponible el principio de estabilidad presupuestaria, escogiendo para ello a un órgano de concepción contramayoritaria como es el Tribunal de Justicia de la UE.

Por último, Gabriel Moreno expone la tesis principal de la obra al inferir, a partir de todos los procesos y mecanismos mentados, una mutación de la 
Constitución económica europea como consecuencia de incorporar la estabilidad presupuestaria al acervo jurídico político comunitario, resultando en la evidente incompatibilidad de este nuevo modelo económico competitivo y político fragmentado con el Estado social, para dar pie finalmente a la nueva «constitución económica neoliberal» de la Unión Europea.

Destaca en esta tercera parte el desarrollo conceptual de la convergencia acaecida en el seno de la Unión Europea entre la teoría Ordoliberal y la Economía constitucional de Buchanan. La primera encuentra su principal reflejo en el «modelo económico competitivo». Puesto que el ordenamiento y jurisprudencia comunitaria exigen el reconocimiento mutuo de ordenamientos jurídicos nacionales como fundamento para el libre mercado en la Unión Europea, se incita así, en una realidad socioeconómica donde el capital es extremadamente voluble, a una constante competición entre ordenamientos jurídicos y fiscales con el fin de volver al Estado más atractivo para las inversiones y el asentamiento del capital, dificultando así las posibilidades recaudatorias de los gobiernos que mantienen a su vez el Estado social, ya de por sí amenazado por la estabilidad presupuestaria, el techo de déficit y el límite a la deuda pública. Además, desde nuestro prisma resulta lógico afirmar que esta competición de ordenamientos nacionales no hace más que quebrantar el principio clave de solidaridad que debería regir la integración Europea, debilitando así el proyecto comunitario. Así mismo, la Escuela constitucional también halla reflejo en la nueva realidad Europea por medio del modelo político fragmentado, ideal promovido por Buchanan según el cual una Unión Europea estancada en la integración política, y por tanto alejada de los patrones federales que reforzasen a un gobierno fuerte interventor, era la mejor forma de establecer una organización supranacional políticamente desestructurada pero capaz de imponer a los gobiernos que la integran unos principios rectores, entre los que destaca la estabilidad presupuestaria, frenando así la extensión del temido leviatán y consiguiendo simultáneamente la constitucionalización de la Golden Rule en los Estados europeos, pretensión definitivamente alcanzada tras la firma del TECG.

Como corolario de estos nuevos modelos políticos y económicos, se desarrollan en el último capítulo de la obra las principales características de la nueva Constitución económica neoliberal de la Unión Europea que, como se habrá podrido desprender de las sucintas claves expuestas en esta recensión, se fundamenta en: la preponderancia del elemento liberal sobre el democrático en cuanto a principios rectores de la Unión Europea, el recurso a opacos procedimientos jurídicos para elevar la estabilidad presupuestaria a la indisponibilidad, la huida hacia el derecho internacional y, en esencia, el progresivo desmantelamiento del Estado social y sus capacidad transformadoras de las realidad nacionales europeas.

Tomando en consideración el complejo y confuso andamiaje sobre el que se han edificado los nuevos procedimientos comunitarios, y lo arduo de rastrear las hondas e interconectadas raíces teóricas neoliberales del mismo, la obra que terminamos aquí de recensionar, en estas necesariamente escuetas páginas, resulta una precisa guía para comprender los nuevos mecanismos en los que se fundamenta la Unión Europea y despejar las incógnitas respecto a algunas de las razones y consecuencias de los mismos. El concienzudo estudio acometido por el profesor de la Universidad de Extremadura sobre los resultados de la institucionalización de la estabilidad presupuestaria en la Unión Europea permite abrir la puerta, lato sensu, a posteriores análisis sobre las incongruencias jurídicas a las que se ha tenido que acudir para lograr dicha institucionalización y sobre las profusas consecuencias en materia constitucional que se nos plantean a partir de ahora. 